\title{
Pemanfaatan Panas Buangan Motor Induk Untuk Menjalankan Sistem Pendingin Pada KM Alalunga
}

\author{
S. D. Pentury ${ }^{1, *}$, G. S. Norimarna ${ }^{2}$, P. Ciptoadi ${ }^{3}$, E. W. Wairisal ${ }^{4}$ \\ ${ }^{1}$ Jurusan Teknik Mesin Fakultas Teknik Universitas Pattimura,Ambon 97233 \\ *dianapentury@gmail.com \\ ${ }^{2}$ Jurusan Teknik Mesin Fakultas Teknik Universitas Pattimura,Ambon 97233 \\ *gnorimarna@yahoo.com \\ ${ }^{3}$ Jurusan Teknik Mesin Fakultas Teknik Universitas Pattimura,Ambon \\ Email : \\ ${ }^{4}$ Jurusan Teknik Mesin Fakultas Teknik Universitas Pattimura,Ambon \\ Email :-
}

\begin{abstract}
Abstrak. Pembakaran bahan bakar pada motor induk KM Alalunga berjenis motor Diesel menghasilkan tenaga efektif hanya $32-40 \%$. Sisanya sebesar $60-70 \%$ terbuang melalui : Air pendinginan $30-33 \%$, gas buang $23-32 \%$, dan sisanya melalui mekanisme radiasi. Dengan menggunakan metode korelasional dimana jumlah energi yang terkandung dalam gas buang dihitung berdasarkan jumah pemakaian bahan bakar dimanfaatkan untuk proses pendinginan muatan berupa ikan. Dari hasil penelitian diperoleh energi yang terkandung dalam gas buang 415064 $\mathrm{kJ} / \mathrm{hr}$, energi tersebut dimanfaatkan untuk proses pendinginan absorpsi uap yang menggunakan generator dengan kapasitas $528 \mathrm{~kJ} / \mathrm{hr}$ untuk mendinginkan produk dengan kapasitas $3579563 \mathrm{~kJ}$.
\end{abstract}

Kata kunci : Gas buang, Pendinginan absorpsi uap, Beban pendingin, Energi generator uap.

\begin{abstract}
Combustion of fuel on main engine KM Alalunga type Diesel Engine produces effective power only $32-40 \%$. The remaining $60-70 \%$ is wasted through :Cooling water $30-33 \%$, Exhaust gas $23-32 \%$ and the rest through the radiation mechanism. By using the correlational method where the amount of energy contained in the exhaust gas is calculated based on the amount of fuel used for the cooling procces of cargo in the form of fish. From the research result the energy contained in the exhaust gas $415064 \mathrm{~kJ} / \mathrm{hr}$. The energy is used for the vapour absorption refrigeration system cooling process using a generator with a capacity of $528 \mathrm{~kJ} / \mathrm{hr}$ to cooling products with a capacity $3579563 \mathrm{~kJ}$.
\end{abstract}

Keywords : Exhaust gas, Vapour Absorption Refrigeration System, Cooling capacity, Energy of steam generator.

\section{PENDAHULUAN}

Jarak tempuh ke lokasi penangkapan yang jauh, metode pengawetan menggunakan es batu yang berpengaruh pada kualitas hasil tanggkapan serta biaya pembelian es batu dan bahan bakar yang cukup tinggi adalah kendala yang serin dihadapi oleh para nelayan.

Energi yang dihasilkan dan diubah menjadi tenaga efektif untuk $1 \mathrm{~kg}$ bahan bakar yang digunakan sebesar $32 \div 40 \%$. $30 \div 33 \%$ tebuang melalui air pendingin, $23 \div 32 \%$ melalui gas buang. Jadi $60 \div$ $70 \%$ energi yang dihasilkan terbuang percuma.[1]. A.Bangotra pada tahun 2017 merancang generator sebagai bagian utama dari sistem pendingin absorpsi, ditempatkan dekat dengan manifold [2]. Di tahun yang sama F. Napitupulu et all mendesain dan melakukan pengujian prototype siklus pendinginan absorpsi sumber tenaganya dari motor pembakaran dalam [3].

M. Becker et all 2018 melakukan simulasi molekuler untuk pendinginan absorpsi [4]. Sedangkan pada penulisan ini berdasarkan ketersediaan energi sebagimana dijelaskan diatas dan beberapa kendala yang dihadapi oleh nelayan penulisan ini betujuan untuk 
menjawab masalah tersebut yakni mengetahui jumlah energi terbuang yang terkandung dalam gas buang pada motor induk KM Alalunga serta kapasitas sistem pendingin ikan yang dapat direncanakan jika memanfaatkan ketersediaan energy tersebut menggunkan sistem pendingin absorpsi uap.

\section{BAHAN DAN METODE}

\subsection{Prosedur Penelitian dan Persamaan}

Metode yang digunakan adalah metode korelasional [5] untuk melihat hubungan sebab akibat, dan bersifat empiris. Menggunakan 2 variabel penelitian yaitu variabel bebas \& terikat, sebagaimana terlihat pada persamaan matematika berikut ini :

$y_{1}=f\left(x_{1}, x_{2}\right)$

dengan $\mathrm{y}_{1}$ adalah jumlah energi terbuang yang terkandung dalam gas buang motor induk $(\mathrm{kJ} / \mathrm{hr}) \mathrm{x}_{1}$ adalah jumlah pemakaian bahan bakar per jam $(\mathrm{kg} / \mathrm{hr}) \mathrm{x}_{2}$ adalah panas yang dihasilkan oleh pembakaran $1 \mathrm{~kg}$ bahan bakar (kcal/hr).

$y_{2}=f\left(x_{3}, x_{4}, x_{5}\right)$

y2 adalah panas yang dibutuhkan oleh generator uap untuk menjalankan sistem $(\mathrm{kJ} / \mathrm{hr}), \mathrm{x}_{3}$ adalah beban pendingin $(\mathrm{kJ}), \mathrm{x}_{4}$ adalah kapasitas pendingin (Ton.hr), dan $\mathrm{x}_{5}$ adalah laju aliran massa refrigeran $(\mathrm{kg} / \mathrm{hr})$. Maka pada prosedur penelitian data yang dijadikan sebagai koefesien korelasi adalah Ukuran Pokok Kapal, Spesifikasi Motor Induk, Ukuran Palka, dan Spesifikasi Muatan. Analisis hasil pengolahan data didasarkan pada persamaan - persamaan berikut :

\section{Panas Yang Terkandung Dalam Gas Buang Motor Induk}

Panas yang terkandung dalam gas buang adalah salah satu komponen neraca panas dengan persentase $23 \div 32$ dari jumlah panas yang dihasilkan oleh Pembakaran 1 kg bahan bakar [1].
$Q_{e g}=(0,23 \div 0,32) Q_{f} \quad \mathrm{~kJ} / \mathrm{hr}$

Perhitungan Beban Kerja Dengan Sistem Pendingin Absorpsi Uap (Vapour Absorption Refrigeration System)

Sistem Pendingin Absorpsi Uap adalah suatu bentuk sistem pendingin dimana sumber energy termal berasal dari matahari, limbah panas, proses pembangkit uap dan gas alam dengan temperatur $100-200^{\circ} \mathrm{C}$ [6]. Sistem pendingin absorpsi uap tergambar sebagai berikut :

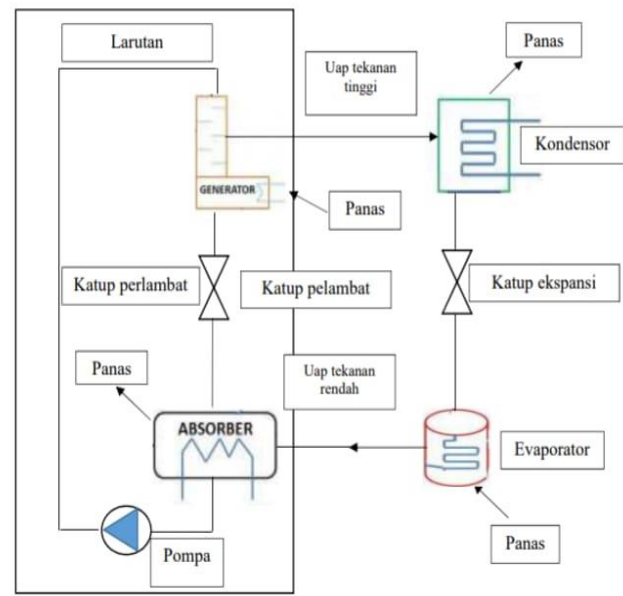

Gambar 1. Sistem pendingin absorpsi uap

Sumber : Refrigeration system (Process engineering equipment guideline)2015.Hal:13

Penentuan Beban Kerja Pada Sistem Pendingin Absorpsi Uap didasarkan pada PH Diagram dan PTX Diagram.



Gambar 2. PH Diagram

Sumber: www.researchgate, net 


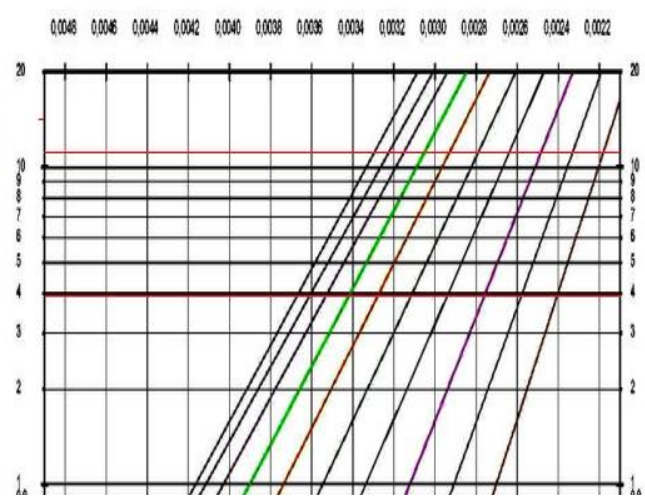

Gambar 3. PTX Diagram

Sumber : $\underline{\text { www.researchgate, net }}$

\section{Beban Pendinginan}

Jumlah energi panas yang harus diserap oleh sistem diperoleh dengan persamaan [7]

$Q_{\text {load }}=m C p \Delta t, \quad \mathrm{~kJ}$

dengan $\mathrm{m}$ adalah massa produk $(\mathrm{kg}), \mathrm{cp}$ adalah panas spesifik produk $\left(\mathrm{kJ} / \mathrm{kg}^{0} \mathrm{C}\right), \Delta \mathrm{T}$ adalah perbedaan temperatur $\left({ }^{0} \mathrm{C}\right)$

\section{Kapasitas Pendinginan}

Kapasitas pendingin adalah kemampuan mesin pendingin untuk mendinginkan subtansi dari sistem. Ton.hr adalah istilah umum yang sering digunakan untuk mengukur dan menentukan kapasitas pendinginan. Dirumuskan dalam persamaan berikut [7]

$T_{r}=\frac{Q_{\text {load }}}{12660,6708}, \quad$ Ton.hr

dengan $\mathrm{Q}_{\text {load }}$ adalah beban pendinginan

\section{Laju Aliran Massa Refrigeran}

Jumlah refrigeran yang mengalir dalam sistem per satuan waktu dirumuskan sebagai berikut [7]

$m_{r}=\frac{T_{r}}{h_{1}-h_{10}}, \mathrm{~kg} / \mathrm{hr}$

dengan $\mathrm{T}_{\mathrm{r}}$ kapasitas (Ton.hr), $\mathrm{h}_{1}$ adalah entalpi refrigeran yang keluar dari evaporator $(\mathrm{kJ} / \mathrm{kg}), \mathrm{h}_{2}$ adalah entalpi larutan yang keluar dari absorber $(\mathrm{kJ} / \mathrm{kg})$

\section{Beban Kerja Evaporator}

Dibutuhkan sejumlah refrigeran untuk menyerap panas dari produk, beban kerja evaporator dirumuskan sebagai berikut [8]

$Q_{\text {evap }}=m_{r}\left(h_{1}-h_{10}\right), \mathrm{kJ} / \mathrm{hr}$

dengan $\mathrm{m}_{\mathrm{r}}$ adalah laju aliran massa, $\mathrm{h}_{1}$ adalah entalpi refrigerant yang keluar dari evaporator $(\mathrm{kJ} / \mathrm{kg}), \quad \mathrm{h}_{10}$ adalah entalpi refrigerant yang masuk ke evaporator $(\mathrm{kJ} / \mathrm{kg})$

\section{Perbandingan Sirkulasi Absorber}

Perbandingan antara laju aliran massa amonia $\mathrm{NH}_{3}$ dan $\mathrm{H}_{2} \mathrm{O}$ dirumuskan sebagai berikut [8]

$\lambda=x_{w s} / x_{s s}-x_{w s}$

dengan $\mathrm{x}_{\mathrm{ws}}$ adalah kosentrasi larutan lemah $(\%), \mathrm{x}_{\mathrm{ss}}$ adalah kosentrasi larutan kuat (\%)

\section{Massa larutan lemah}

Air dengan sedikit kosentrasi ammonia disalurkan dari generator ke absorber dirumuskan sebagai berikut [8]

$m_{w s}=(1+\lambda) m_{r} \mathrm{~kg} / \mathrm{s}$

dengan $\lambda$ adalah perbandingan sirkulasi

\section{Massa larutan kuat}

Larutan air dan amonia yang keluar dari absorber dipompakan ke generator, dirumuskan sebagai berikut [8]

$m_{s s}=\lambda m_{r} \quad \mathrm{~kg} / \mathrm{s}$

\section{Beban Kerja Absorber}

Panas yang terkandung dalam uap refrigeran akan dilepaskan ke media pendingin dan berubah menjadi cair, dirumuskan sebagai berikut [8]

$Q_{a b s o r b}=m_{r} h_{1}+m_{w s} h_{2}-m_{s s} h_{5}, \mathrm{~kJ} / \mathrm{hr}(11)$

dengan $\mathrm{h}_{5}$ adalah entalpi larutan yang keluar dari absorber, $\mathrm{kJ} / \mathrm{kg}$ 


\section{Penukar Panas}

Larutan kuat dengan temperatur tinggi dari generator mengalir ke Heat Exchanger dan akan melepaskan panas. Dengan perumusan sebagai berikut [9]

$m_{w s}\left(h_{7}-h_{6}\right)=m_{s s}\left(h_{4}-h_{3}\right), \mathrm{kJ} / \mathrm{kg}(12)$

$\mathrm{h}_{7}$ adalah entalpi larutan yang keluar dari penukar panas $(\mathrm{kJ} / \mathrm{kg}), \mathrm{h}_{6}$ adalah entalpi larutan yang keluar dari pompa $(\mathrm{kJ} / \mathrm{kg}), \mathrm{h}_{4}$ adalah entalpi larutan yang masuk ke penukar panas $(\mathrm{kJ} / \mathrm{kg})$

\section{Generator}

Generator uap dibutuhkan untuk memisahkan larutan refrigeran $\left(\mathrm{NH}_{3} \mathrm{H}_{2} \mathrm{O}\right)$ dari absorber sehingga refrigeran cair dapat disalurkan ke generator dengan menggunakan pompa. Dirumuskan sebagai berikut [9]

$Q_{\text {gen }}=m_{r} h_{8}+m_{s s} h_{4}+m_{w s} h_{7}, \mathrm{~kJ} / \mathrm{hr}$

$\mathrm{h}_{8}$ adalah entalpi refrigeran yang keluar dari generator $(\mathrm{kJ} / \mathrm{kg})$

\section{Kondensor}

Beban panas akan dilepaskan di kondensor. Dirumuskan sebagai berikut [9]

$Q_{\text {con }}=m_{r}\left(h_{8}-h_{9}\right), \quad \mathrm{kJ} / \mathrm{hr}$

$\mathrm{h}_{9}$ adalah entalpi refrigeran yang keluar dari kondensor (kJ/kg) [9]

\section{Koefesien Kerja}

Perbandingan antara kerja yang dihasilkan dan kerja yang dibutuhkan oleh sistem pendingin. Dirumuskan sebagai berikut [10]

$C O P=\frac{Q_{\text {evap }}}{Q_{\text {gen }}}$

\section{HASIL DAN PEMBAHASAN}

Panas yang terkandung dalam gas buang motor induk.

Jumlah pemakaian bahan bakar per jam untuk motor induk Yanmar 6 CH-UTE sebesar 42,676 kg/hr, dengan jumlah panas yang dihasilkan oleh pembakaran $1 \mathrm{~kg}$ bahan bakar sebesar $4321027.6 \mathrm{kcal} / \mathrm{hr}$, maka jumlah panas yang terkandung dalam gas buang motor induk sebesar 415064,061806 $\mathrm{kJ} / \mathrm{hr}$.

\section{Perhitungan beban panas produk}

Gambar kerja bertujuan untuk mengambarkan entalpi masuk keluar pada setiap sistem, sehingga perhitungan beban panas produk.

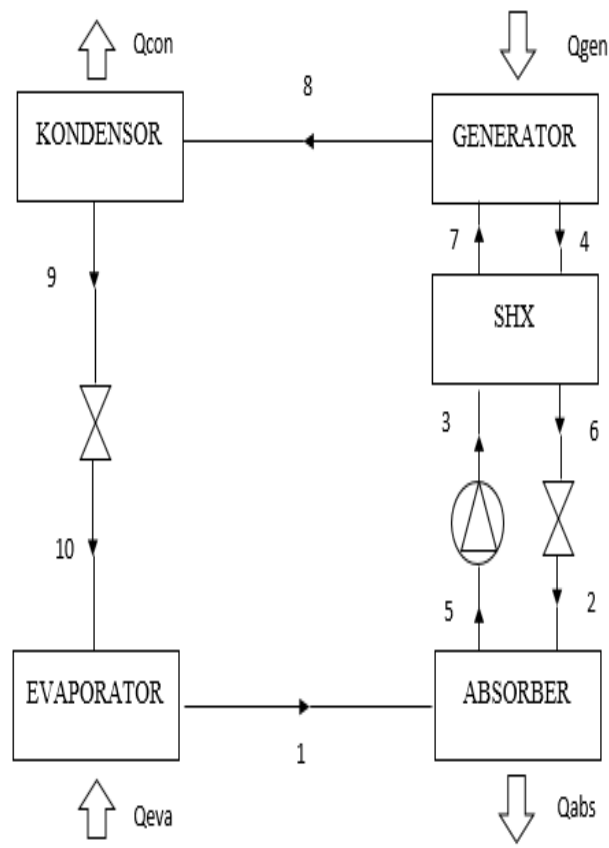

Gambar 4. Kerja Sistem Pendingin Absorpsi Uap 
Temperatur kerja kondensor $32^{\circ} \mathrm{C}$ Temperatur kerja evaporator $-2^{0} \mathrm{C}$, berdasarkan diagram P-H dan PTX diperoleh karakteristik refrigeran R717.

Tabel 1. Karakteristik Refrigeran

\begin{tabular}{|c|c|c|c|c|c|}
\hline Poin & $\begin{array}{c}\mathbf{P} \\
\text { (Bar) }\end{array}$ & $\begin{array}{c}\mathrm{T} \\
\left({ }^{0} \mathrm{C}\right)\end{array}$ & $\begin{array}{l}\mathrm{X} \\
(\%)\end{array}$ & $\begin{array}{c}\mathrm{H} \\
(\mathrm{kJ} / \mathrm{kg})\end{array}$ & Fase \\
\hline 1 & 3,9819 & 31 & 100 & 1325 & $\begin{array}{l}\text { Uap } \\
\text { jenuh }\end{array}$ \\
\hline 2 & 3,9819 & 43 & 41 & $-43,75$ & $\begin{array}{c}\text { Larutan } \\
\text { lemah }\end{array}$ \\
\hline 3 & 12,382 & 65 & 54 & 56,25 & $\begin{array}{c}\text { Larutan } \\
\text { lemah }\end{array}$ \\
\hline 4 & 12,382 & 90 & 38 & 187,5 & $\begin{array}{c}\text { Larutan } \\
\text { lemah }\end{array}$ \\
\hline 5 & 3,9819 & 50 & 37 & 6,25 & $\begin{array}{c}\text { Larutan } \\
\text { kuat }\end{array}$ \\
\hline 6 & 12,382 & 50 & 66 & 18,75 & $\begin{array}{c}\text { Larutan } \\
\text { kuat }\end{array}$ \\
\hline 7 & 12,382 & 75 & 47 & 134,25 & $\begin{array}{c}\text { Larutan } \\
\text { kuat }\end{array}$ \\
\hline 8 & 12,382 & 61 & 100 & 1575 & $\begin{array}{l}\text { Uap } \\
\text { jenuh }\end{array}$ \\
\hline 9 & 12,382 & 31 & 100 & 345,85 & $\begin{array}{c}\text { Cairan } \\
\text { jenuh }\end{array}$ \\
\hline 10 & 3,9819 & -1 & 100 & 345,85 & $\begin{array}{c}\text { Cairan } \\
\text { jenuh }\end{array}$ \\
\hline
\end{tabular}

\section{Beban Pendinginan}

Panas spesifik $\left(\mathrm{c}_{\mathrm{p}}\right)$ ikan sebesar 0.88 $\mathrm{kJ} / \mathrm{kg}^{0} \mathrm{C}$, selisih entalpi $(\Delta \mathrm{T})$ sebesar $34^{0} \mathrm{C}$, maka jumlah energi panas yang harus diserap oleh sistem sebesar 3579562,523669 $\mathrm{kJ}$.

\section{Kapasitas Pendinginan}

Beban pendinginan sebesar 3579562,523669 $\mathrm{kJ}$ berakibat kapasitas pendinginan pada sistem sebesar 282,4332502 Ton.hr kapasitas pendinginan sama dengan beban panas pada evaporator.

\section{Laju Aliran Massa}

Berdasarkan karakteristik refrigeran $\mathrm{R} 717$ poin 1 dan 10 (Entalpi), maka jumlah refirgeran yang mengalir dalam sistem sebesar $0,288447378 \mathrm{~kg} / \mathrm{hr}$.

\section{Perbandingan Sirkulasi Absorber}

Konsentrasi larutan lemah sebesar 0.44, dan kosentrasi larutan kuat sebesar 0.5 sehingga, perbandingan antara laju aliran masa amonia $\left(\mathrm{NH}_{3}\right)$ dan air $\left(\mathrm{H}_{2} \mathrm{O}\right)$ sebesar 7,333333333.

\section{Massa larutan kuat dan lemah}

Massa larutan lemah $\left(\mathrm{H}_{2} \mathrm{O}\right)$ sebesar $2,403728108 \mathrm{~kg} / \mathrm{hr}$ dan massa larutan kuat $\left(\mathrm{NH}_{3}\right)$ sebesar $2,115280735 \mathrm{~kg} / \mathrm{hr}$.

\section{Beban Kerja Absorber}

Laju aliran massa sebesar 0,288447378, dengan Entalpi pada poin 1,2 dan 5, maka beban kerja dari absorber adalah sebesar $263,8091666 \mathrm{~kJ} / \mathrm{hr}$.

\section{Penukar Panas}

Pada penukar panas yang diperoleh adalah entalpi, yaitu sebesar $134,25 \mathrm{~kJ} / \mathrm{kg}$.

\section{Generator}

Beban kerja dari generator uap adalah sebesar 528,2192579 kJ/hr.

\section{Kondensor}

Panas yang harus dilepaskan oleh kondensor adalah sebesar $354,5450947 \mathrm{~kJ} / \mathrm{hr}$.

\section{Koefesien kerja}

Hasil perbandingan dari kerja yang dihasilkan dengan kerja yang dibutuhkan adalah sebesar $53 \%$. 
Persentase muatan palka dengan energi yang dibutuhkan

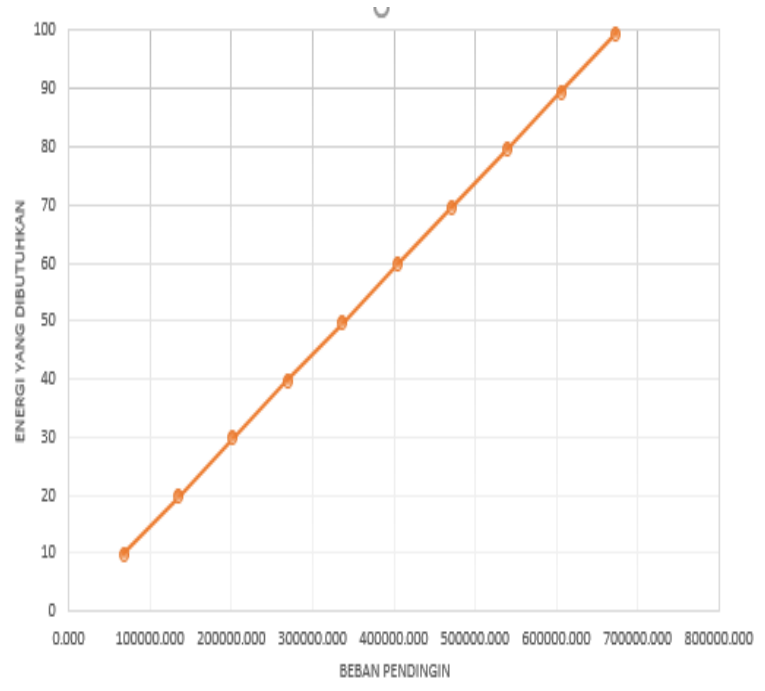

Gambar 5. Grafik persentase muatan palka depan dengan energi yang dibutuhkan

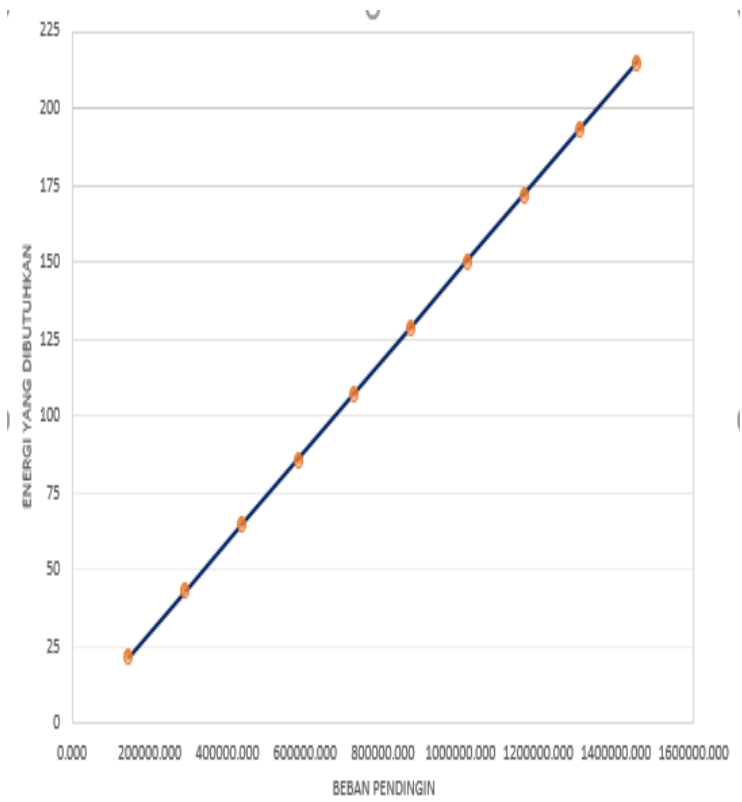

Gambar 6. Grafik persentase muatan palka tengah dan belakang dengan energi yang dibutuhkan.

\section{Kebutuhan Energi Total}

Perbandingan beban pendingin dengan energi yang dibutuhkan tiap palka terlihat pada tabel berikut :
Tabel 2. Perbandingan beban pendingin dengan energi yang dibutuhkan

\begin{tabular}{|l|l|c|}
\hline \multicolumn{1}{|c|}{ Palka } & $\begin{array}{c}\text { Beban Pendinginan } \\
(\mathrm{kJ})\end{array}$ & $\begin{array}{c}\text { Energi yang } \\
\text { dibutuhkan } \\
(\mathrm{kJ} / \mathrm{hr}\end{array}$ \\
\hline Depan & 673351,9838 & 99,46810334 \\
Tengah & 1453953,972 & 214,6463159 \\
Belakang & 1453953,972 & 214,6463159 \\
Total & 3579459,928 & 528,7607357 \\
\hline
\end{tabular}

\section{KESIMPULAN}

Berdasarkan data pengukuran, perhitungan, dan analisis yang telah dilakukan, maka dapat disimpulkan bahwa :

1. $23 \div 32 \%$ panas yang dihasilkan dari gas buang motor induk Yanmar $6 \mathrm{CH}$ UTE dengan pemakaian bahan bakar sebesar $42 \mathrm{~kg} / \mathrm{hr}$ menghasilkan panas sebagai sumber energi untuk menjalankan sistem pendingin absorpsi uap sebesar $415064 \mathrm{~kJ} / \mathrm{hr}$.

2. Energi yang dibutuhkan oleh generator untuk menjalankan sistem pendinginan absorpsi uap adalah sebesar $528 \mathrm{~kJ} / \mathrm{h}$ dengan demikian $\mathrm{Q}_{\text {eg }}>\mathrm{Q}_{\text {gen }}$ maka panas buangan motor induk dapat digunakan untuk menjalankan sistem pendingin absorpsi uap.

\section{DAFTAR PUSTAKA}

[1] Petrovsky, N., 1976 Marine Internal Combustion Engine:Mik Publishers Mosccow.

[2] B. Arun (2017), Design - Analysis Of Generator Of Vapour Absorption Refrigeration System For Automotive Air Conditioning. International Journal Of Engineering Research \& Technology, 06 june-2017.

[3] F. Napitupullu, F. Daulay, P. Dedy, Jecson (2017), A Preliminary Study On Designing and Testing of an Absorption Refrigeration Cycle Powered by Exhaust Gas of Combustion Engine. IOP Conference Series: Material Science and Enginering 16 - 18 November 2016. 
[4] M. Becker, W. Meng, K. Abhishek, J. Seyed, R. Mahinder, D. David, Absorptiomn Refrigeration Cycles With Ammonia - Ionic Liquid Working Pairs Studied By Moleculer Simulation. ACS Publications March 2018.

[5] V. Srikanth, N. Raja, Gupta (2017) Thermodynamic Analysis of Vapour Absorption Refrigeration System Using Solar Energy. International Journal of Latest Trends in Engineering and Technologi.

[6] P. Matta, SaiKiran, Khaja, Manoj (2017) Design Of Vapour Absorption Refrigeration System Of 1.5tr Capacity By Waste Heat Recovery Process. International Journal of Pure and Applied Mathematics Volume 115 No. 7 2017, 613-619.

[7] K. Rixon, T. Sanoj, C. Mathew, T. Thomas . Air Cooling Inside Vehicles using Vapour Absorption Refrigeration System International Journal of Engineering Research \& Technology (IJERT) ISSN: $2278 \quad-0181$ IJERTV4IS120215 www.ijert.org (This work is licensed under a Creative Commons Attribution 4.0 International License.) Vol. 4 Issue 12, December2015

[8] A. Shukla, A. Mishra, D. Shukla, K. Chauhan. C.O.P Derivation and Thermodynamic Calculation of Ammonia-Water Vapor Absorption Refrigeration System. ISSN 0976 6340 (print) issn $0976-6359$ (online) volume 6, issue 5, may (2015), pp. 7281.

[9] VR. Rajesh, S.Salim (2016) Thermodynamic Analysis of Aqua Ammonia Based Miniaturixed Vapour Absorption Refrigeration System Utilizing Solar Thermal Energy 2016.

[10] J. Sahadev, M. Arulprakasajothi, U. Chandrasekhar, D Yuvarajan (2019) Experimental Investigation of Vapour Absorption Refrigeration Cycle for Automibile Cabin Cooling 2019. 